\title{
Oncogenic human papillomaviruses and ploidy in cervical lesions
}

\author{
S Rihet, M Lorenzato, C Clavel
}

\begin{abstract}
Aim-To compare ploidy measurements obtained on tissue sections of selected low and high grade squamous intraepithelial lesions containing oncogenic HPV (types 16,18 or 33 ) detected by in situ hybridisation (ISH) or PCR.

Methods-DNA ploidy was assessed by image cytometry after Feulgen staining of contiguous serial sections of eight lesions exhibiting atypical squamous cells or squamous atypia and 53 low and 63 high grade squamous intraepithelial lesions in which HPV had been detected by ISH or PCR.

Results-Aneuploidy was strongly associated with the presence of oncogenic HPV, being detected in $50 \%$ of lesions with squamous atypia and $75.5 \%$ of the low and $95.2 \%$ of the high grade squamous intraepithelial lesions. The multiploid profile was highly associated with high grade lesions and with the pattern of HPV DNA integration.

Conclusions-The presence of aneuploidy is strongly suggestive of the presence of oncogenic HPV types. Combining the detection of HPV by ISH and PCR with DNA image cytometry may provide the pathologist and the physician with important prognostic information about low grade lesions, especially when these lesions have a multiploid DNA profile and contain oncogenic HPV.

(F Clin Pathol 1996;49:892-896)
\end{abstract}

Keywords: cervical intraepithelial neoplasia, oncogenic human papillomavirus, ploidy.

There is increasing evidence, from molecular biology studies, ${ }^{1}$ epidemiological investigations $^{23}$ and clinical observations, ${ }^{4}$ that human papillomavirus (HPV) is an aetiological agent in cervical carcinogenesis. More than $70 \mathrm{HPV}$ types have been identified to date. HPV types $6,11,42,43$, and 44 are regarded as low risk, and types $16,18,33$, and several others as high risk. $^{5}$

Detection of oncogenic HPV types has been proposed as a method of evaluating the prognosis of low grade squamous intraepithelial lesions, such as condylomas and grade I cervical intraepithelial neoplasia $(\mathrm{CIN} \mathrm{I})^{67}$ or to detect high grade squamous intraepithelial lesions (including CIN II and III) in women with minor smear abnormalities. ${ }^{8}$ However, Downey et $a l^{9}$ showed that a histological diagnosis of low grade cervical disease was a better long term predictor of disease progression than HPV type 16 positivity.

Thus, the prognostic significance of detecting high risk HPV DNA in low grade squamous intraepithelial lesions is still a matter of debate. The presence of high risk HPV does not necessarily lead to carcinogenesis. The possibility of regression of lesions containing HPV has been well established and has been estimated by Syrjänen ${ }^{10}$ to occur in $40 \%$ of patients. The role(s) of cofactors (immunosuppression, pregnancy, tobacco, microtraumas, nutritional and hormonal factors, number of sexual partners, and infections) in the progression of these lesions cannot be ignored. ${ }^{11}$ The persistence of high risk HPV in dysplastic cervical lesions has also been found to be associated with progressive disease. ${ }^{12}$

DNA can be analysed using a variety of techniques, including flow cytometry, ${ }^{13-15}$ computerised digital imaging and image cytometry after Feulgen staining. ${ }^{16-25}$ The DNA ploidy profile seems to be a useful indicator of prognosis in CIN. In a retrospective study of 100 women with all grades of CIN, Fu et $a l^{2}$ reported that, of 64 lesions that regressed, $85 \%$ were euploid and $15 \%$ were aneuploid. By contrast, of 58 lesions that persisted, $95 \%$ were aneuploid. All eight lesions that progressed to invasive cancer were aneuploid. Bibbo et $a l^{16}$ also showed that CIN lesions with a diploid profile were more likely to return to normal than those exhibiting an aneuploid pattern.

Nevertheless, while reports of ploidy or HPV detection in cervical lesions are numerous, few authors have used both approaches in parallel. ${ }^{17-19}$

The aim of the present study was to compare ploidy measurements obtained on tissue sections of selected low and high grade squamous intraepithelial lesions containing oncogenic HPV (types 16,18 or 33) detected by in situ hybridisation (ISH) or PCR. DNA ploidy was assessed by image cytometry after Feulgen staining of contiguous serial sections of the same lesions in which HPV had been detected by ISH or PCR. This approach may provide more information as to the nature and evolution of low grade squamous intraepithelial lesions.

\section{Methods}

The study population comprised 115 patients with biopsy $(\mathrm{n}=124)$ proven high risk HPV (types 16,18 or 33 ) infection. Eight specimens exhibited squamous atypia (mean patient age 30 years), and 53 were low grade (flat condylomas and CIN I; mean patient age 29 years) and 

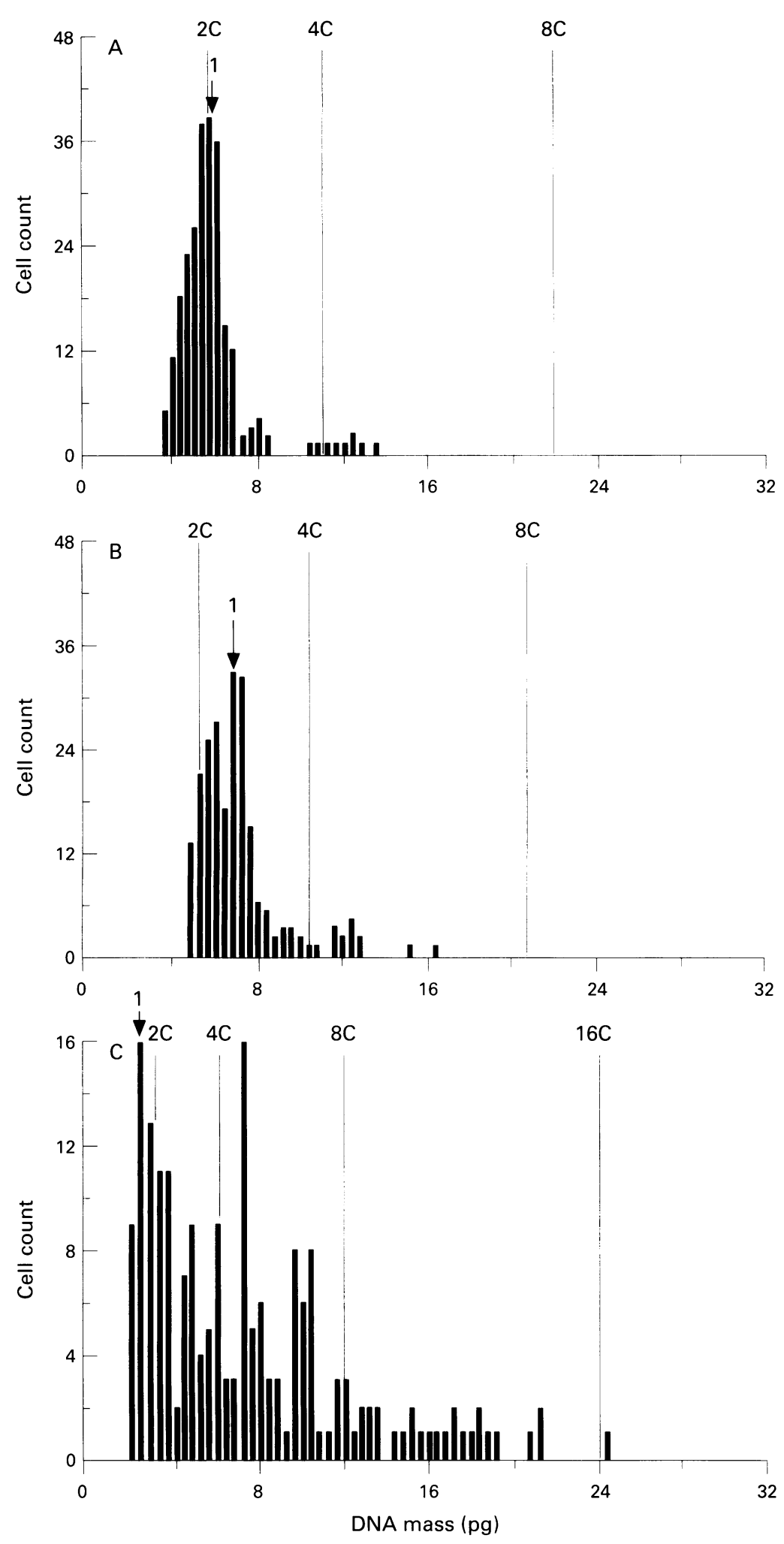

Figure 1 DNA quantification on $6 \mu \mathrm{m}$ sections. (A) Diploid profile; (B) single peak aneuploid profile; (C) multiploid profile (arrows indicate main cell population peaks).

63 high grade ( $32 \mathrm{CIN}$ II and $31 \mathrm{CIN}$ III; mean patient age 34 years) squamous intraepithelial lesions. Both low (except squamous atypia) and high grade squamous intraepithelial lesions displayed koilocytosis, which is evocative of HPV infection. HPV DNA was detected by ISH or PCR, or both.

Sixteen serial sections $(3-6 \mu \mathrm{m})$ of each biopsy specimen were used as follows: the first section was for conventional diagnosis, three for ISH, one for Feulgen staining and DNA quantification, 10 for PCR, and the last to confirm that the entire series was still within the initial lesion. When this lesion was not found or was of a different grade, the case was excluded from the study.

Oncogenic HPV was detected by ISH using digoxigenin labelled probes applied to formalin fixed, paraffin wax embedded tissue sections, as described previously. ${ }^{26}$ Positive controls for ISH and PCR comprised CaSki cells (HPV 16), HeLa cells (HPV 18) and CKEJ cells (HPV 33); negative controls comprised the pBR 322 plasmid and water. Although Southern blotting is the reference technique for the detection of integrated HPV DNA, this procedure is cumbersome and cannot be used in routine analyses. Therefore, we applied the relevant criteria of Cooper $e t a l^{7}$ to assess viral integration by ISH in tissue sections of the same biopsy sample: a diffuse signal throughout the nucleus corresponds to episomal HPV DNA and a punctate signal to integrated HPV DNA.

In some specimens whose histological patterns were suggestive of HPV infection but were negative by ISH, HPV DNA was extracted from contiguous serial sections and subjected to PCR, using the AMPLICIS kit (CIS Biointernational, Gif-sur-Yvette, France) which amplifies the E6 and E7 regions of HPV types 16 and $18 .^{28}$

DNA QUANTIFICATION

DNA was quantified by image cytometry using the CAS 200 image analysis system (Becton Dickinson, Leiden, The Netherlands) with the ploidy measurement software set at the "tissue section" option. ${ }^{29}$ One contiguous $6 \mu \mathrm{m}$ paraffin wax section of each biopsy specimen was analysed. The wax was dissolved and tissue sections were rehydrated, hydrolysed for 60 minutes $(5 \mathrm{~N} \mathrm{HCl})$ and stained with Feulgen stain.

The calibration slides were those recommended by the CAS system-that is, imprints of fresh rat liver. For the ploidy measurement software, at least 20 calibration cells were required to proceed to the quantification section. The cells were chosen by the computer and the user could accept or reject each cell. The coefficient of variation for the calibration histograms was always less than $3 \%$.

Other reference cells to control for diploidy were chosen systematically outside the lesion but within the same tissue section (40 normal fibroblasts or normal cervical epithelial cells). To quantify DNA in the cervical cell nuclei, at least 200 cells were evaluated where possible.

The results are given with the DNA index (DI) which represents the ratio of the DNA content of the analysed nuclei to the DNA content of the reference cells in $G_{0} / G_{1}$ phase. By definition, the DI of a diploid population is 1 (fig $1 \mathrm{~A})$. The tetraploid pattern $(\mathrm{DI}=2$ ) was grouped with the diploid cases. When the index was different from 1 or 2 , the cell was regarded as aneuploid. In this study, we observed two aneuploid profiles: a single aneuploid peak (fig 1B) or several aneuploid peaks (multiploid profile; fig 1C). 
Table 1 The various types of HPV found in lesions with squamous atypica, and low and high grade squamous intraepithelial lesions with diploid, single peak aneuploid and multipoid profiles. Results are expressed as $n$ (\%)

\begin{tabular}{|c|c|c|c|c|c|c|c|c|c|c|c|c|}
\hline \multirow[t]{3}{*}{ HPV type } & \multicolumn{3}{|c|}{ Squamous atypia } & \multicolumn{4}{|c|}{ Low grade squamous intraepithelial lesions } & \multicolumn{4}{|c|}{ High grade intraepithelial lesions } & \multirow[t]{3}{*}{ Total (\%) } \\
\hline & \multirow[t]{2}{*}{ Diploid } & \multirow{2}{*}{$\frac{\text { Aneuploid }}{\text { (single peak) }}$} & \multirow[t]{2}{*}{ Total } & \multirow[t]{2}{*}{ Diploid } & \multicolumn{2}{|l|}{ Aneuploid } & \multirow[t]{2}{*}{ Total } & \multirow[t]{2}{*}{ Diploid } & \multicolumn{2}{|l|}{ Aneuploid } & \multirow[t]{2}{*}{ Total } & \\
\hline & & & & & Single peak & Multiploid & & & Single peak & Multiploid & & \\
\hline 16 & $3(60.0)$ & $2(40.0)$ & $5(62.5)$ & $6(20.7)$ & $14(48.3)$ & $9(31)$ & $29(54.7)$ & $2(4.5)$ & $9(20.5)$ & $33(75.0)$ & $44(69.8)$ & $78(63.0)$ \\
\hline 18 & 0 & $1(100)$ & $1(12.5)$ & $5(55.5)$ & $2(22.2)$ & $2(22.2)$ & $9(17.0)$ & 0 & $3(50.0)$ & $3(50.0)$ & $6(9.5)$ & $16(12.9)$ \\
\hline 16 and 18 & $1(100)$ & 0 & $1(12.5)$ & $1(33.3)$ & $1(33.3)$ & $1(33.3)$ & $3(5.7)$ & 0 & $2(50.0)$ & $2(50.0)$ & $4(6.4)$ & $8(6.4)$ \\
\hline 33 & 0 & $1(100)$ & $1(12.5)$ & $1(8.3)$ & $4(33.3)$ & $7(58.3)$ & $12(22.6)$ & $1(11.0)$ & $4(44.5)$ & $4(44.5)$ & $9(14.3)$ & $22(17.7)$ \\
\hline Total & $4(50.0)$ & $4(50.0)$ & 8 & $13(24.5)$ & $21(39.6)$ & $19(35.9)$ & 53 & $3(4.8)$ & $18(28.6)$ & $42(66.7)$ & 63 & 124 \\
\hline
\end{tabular}

Table 2 The number of integrated and episomal forms of HPV in the various lesions. Results are expressed as $n(\%)$

\begin{tabular}{|c|c|c|c|c|c|}
\hline \multirow[t]{2}{*}{ Lesion } & \multicolumn{3}{|l|}{ ISH } & \multirow{2}{*}{$\begin{array}{l}P C R \\
\text { (total) }\end{array}$} & \multirow[t]{2}{*}{ Total } \\
\hline & Integrated & Episomal & Total & & \\
\hline Squamous atypia & 0 & $4(100)$ & $4(50.0)$ & $4(50.0)$ & 8 \\
\hline LSIL & $28(66.7)$ & $14(33.3)$ & $42(79.3)$ & $11(20.7)$ & 53 \\
\hline HSIL & $42(91.3)^{\star}$ & $4(8.7)$ & $46(73.0)$ & $17(27.0)$ & 63 \\
\hline Total & $70(76.0)$ & $22(24.0)$ & 92 & 32 & 124 \\
\hline
\end{tabular}

${ }^{\star} \chi^{2}=11.70 ; 1 \mathrm{DF} ; \mathrm{p}<0.001$.

LSIL = low grade squamous intraepithelial lesion; HSIL = high grade squamous intraepithelial lesion.
LOW GRADE INTRAEPITHELIAL LESIONS (FLAT CONDYLOMAS AND CIN I)

Again, the predominant oncogenic HPV was type $16(54.7 \%)$ (table 1). HPV DNA was detected by ISH in the majority of cases $(79.3 \%)$ and the integrated form in $66.7 \%$ of these. HPV DNA was detected by PCR in the remaining $11(20.7 \%)$ cases (table 2$)$.

Aneuploidy profiles were recorded for 40 cases (75.5\%): 21 (39.6\%) exhibited a single aneuploid peak on the histogram, whereas 19 $(35.9 \%)$ had a multiploid profile (table 1 ).

STATISTICAL ANALYSIS

In bivariate analyses, the association between: HPV type and ploidy, the grading of the cervical lesions and ploidy and then the integration pattern, and lastly, the integration pattern and multiploidy, were examined using the $\chi^{2}$ test or a corrected $\chi^{2}$ test (Yates's correction for small samples). For statistical analyses, squamous atypia were regarded as low grade lesions.

\section{Results}

In all cervical specimens, the predominant oncogenic HPV was type $16(63 \%)$ (table 1 ). Of the 124 specimens examined, 20 were diploid and 104 aneuploid: 43 exhibited a single aneuploid peak, whereas 61 had multiploid profiles. There was no significant correlation between the HPV type and aneuploidy $\left(\chi_{c}{ }^{2}=\right.$ $2.87 ; 3 \mathrm{DF} ; \mathrm{NS}$ ) (table 1 ). The frequencies of aneuploidy (single peak and multiploidy) and multiploidy as a function of the grade of the cervical lesion increased significantly $\left(\chi^{2}=\right.$ $12.23 ; 1 \mathrm{DF} ; \mathrm{p}<0.001$ and $\chi^{2}=15.64 ; 1 \mathrm{DF}$; $\mathrm{p}<0.001$, respectively; table 1 ).

LESIONS EXHIBITING SQUAMOUS ATYPIA

HPV was detected in eight patients, predominantly type $16(n=5)$ and one case each of the other oncogenic types (table 1). HPV DNA was detected by ISH in four cases and by PCR in the remainder (table 2). Integrated HPV DNA was not detected by ISH in these lesions. These lesions had single peak aneuploid and diploid profiles (fig 1B).

\section{HIGH GRADE INTRAEPITHELIAL LESIONS (CIN II} AND III)

HPV type 16 was detected in $69.8 \%$ of cases, whereas types 18, 33, and 16 and 18 were found, respectively, in $9.5,14.3$ and $6.4 \%$ of cases (table 1). HPV DNA was detected by ISH in $46(73.0 \%)$ of the 63 patients; integrated DNA was found in 42 (91.3\%). HPV DNA was detected by PCR in 17 $(27.0 \%)$ patients (table 2$)$. The integrated form was found significantly more frequently in high grade lesions $\left(\chi^{2}=11.70 ; 1 \mathrm{DF} ; \mathrm{p}<\right.$ 0.001 ).

Aneuploid profiles were observed in 60 (95.2\%) cases: $18(28.6 \%)$ exhibited a single aneuploid peak, whereas $42(66.7 \%)$ has a multiploid profile (table 1); the latter profile was present in $28(90.3 \%)$ of the $31 \mathrm{CIN}$ III lesions.

Low grade lesions were also observed in 10 sections containing CIN III lesions with a multiploid profile. These low grade lesions harboured the same HPV type and were multiploid. These results were excluded from the analysis. method of detecting HPV DNA is shown in table 3. Aneuploidy was strongly associated with cervical lesions containing oncogenic HPV, being detected in $50 \%$ of lesions exhibiting squamous atypia, $75.5 \%$ of the low grade and $95.2 \%$ of the high grade intraepithelial lesions. Aneuploidy was found mainly in
A comparison of ploidy as a function of the

Table 3 Comparative results of ploidy measurements of HPV DNA according to the method of detection. Results are expressed as $n(\%)$

\begin{tabular}{|c|c|c|c|c|c|c|c|}
\hline \multirow[t]{2}{*}{ Lesion } & \multicolumn{3}{|l|}{ Aneuploid } & \multicolumn{3}{|l|}{ Diploid } & \multirow[t]{2}{*}{ Total } \\
\hline & ISH & $P C R$ & Total & ISH & $P C R$ & Total & \\
\hline Squamous atypia & $3(75.0)$ & $1(25.0)$ & $4(50.0)$ & $1(25.0)$ & $3(75.0)$ & $4(50.0)$ & 8 \\
\hline LSIL & $34(85.0)$ & $6(15.0)$ & $40(75.5)$ & $8(61.5)$ & $5(38.5)$ & $13(24.5)$ & 53 \\
\hline HSIL & $45(75.0)$ & $15(25.0)$ & $60(95.2)$ & $1(33.3)$ & $2(66.7)$ & $3(4.8)$ & 63 \\
\hline Total & $82(78.8)$ & $22(21.2)$ & $104(83.9)$ & $10(50.0)$ & $10(50.0)$ & $20(16.1)$ & 124 \\
\hline
\end{tabular}

LSIL = low grade squamous intraepithelial lesion; HSIL = high grade squamous intraepithelial lesion. 
Table 4 Relation between ploidy and HPV integration. Results are expressed as $n$ (\%)

\begin{tabular}{|c|c|c|c|}
\hline \multirow[t]{2}{*}{ Ploidy } & \multicolumn{2}{|l|}{ ISH } & \multirow[t]{2}{*}{ Total } \\
\hline & Integrated & Episomal & \\
\hline Multiploid & $50(92.6)^{\star}$ & $4(7.4)$ & $54(58.7)$ \\
\hline $\begin{array}{l}\text { Aneuploid } \\
\text { (single peak) }\end{array}$ & $13(46.4)$ & $15(53.6)$ & $28(30.4)$ \\
\hline Diploid & $5(50.0)$ & $5(50.0)$ & $10(10.9)$ \\
\hline Total & $70(76.1)$ & $22(23.9)$ & 92 \\
\hline
\end{tabular}

${ }^{\star} \chi^{2}=23.66 ; 1$ DF; $p<0.001$.

lesions in which oncogenic HPV were detected by ISH ( $85 \%$ of low grade and $75 \%$ of high grade intraepithelial lesions).

Table 4 shows the relation between ploidy and the pattern of HPV DNA integration into the host genome according to the criteria of Cooper et al. ${ }^{27}$

Aneuploidy did not correlate significantly with the pattern of integration $\left(\chi^{2}=2.09 ; 1 \mathrm{DF}_{\text {; }}\right.$ $\mathrm{p}<0.001)$. By contrast, multiploidy correlated significantly with the integrated form in $92.6 \%$ of cases $\left(\chi^{2}=23.66 ; 1 \mathrm{DF} ; \mathrm{p}<0.001\right)$.

\section{FOLLOW UP}

Of the nine patients who underwent two successive biopsies, six were followed but received no treatment (mean follow up 12 months). One low grade lesion persisted but changed from diploid to a single peak aneuploid profile over 18 months. Two low grade lesions with a single peak aneuploid profile progressed to high grade disease with a multiploid profile over two and 33 months, respectively. One low grade lesion with a multiploid profile progressed to high grade disease with a persistent multiploid profile over eight months. Two CIN II lesions progressed to CIN III with one exhibiting a single aneuploid peak becoming multiploid over two months whereas the other was persistently multiploid. In all of these cases the same HPV type (HPV 16) was detected in successive biopsy specimens.

\section{Discussion}

The present results clearly demonstrate a strong association between aneuploidy and the presence of oncogenic HPV. Aneuploidy was detected in $50 \%$ of lesions exhibiting squamous atypia, and in $75.5 \%$ of low grade and $95.2 \%$ of high grade intraepithelial lesions. These findings suggest that aneuploidy is an early event in carcinogenesis, particularly in the presence of oncogenic HPV.

The acquisition of progressive genetic abnormalities, including the development of aneuploidy, has been described for cells immortalised by HPV types 16,18 or $33 .^{30-32}$ HPV may alter regulation of the cell cycle in infected cells via several mechanisms. The HPV E6 and E7 gene products bind p53 and retinoblastoma tumour suppressor proteins and these specific interactions may play a role in the promotion of increased proliferation. The DNA in actively replicating cells becomes more susceptible to injury than that in resting cells, especially when p53 is defective. There- fore, it is plausible that the presence of HPV types 16,18 or 33 induces genetic instability of the host cell genome, ultimately resulting in the development of multiple chromosomal abnormalities and aneuploidy.

We did not find a significant relation between the type of oncogenic HPV and the presence of aneuploidy, although HPV type 18 was less frequently associated with this DNA profile.

If we consider published data on the presence of aneuploidy in all low grade lesions irrespective of the presence of HPV or if HPV DNA was detected, regardless of its type, the frequency of aneuploidy varied from $0 \%{ }^{14}$ to $57 \%{ }^{13}$ in flow cytometry studies. However, this methodology is not very selective and can include normal epithelial cervical and mesenchymal cell DNA. In our study, we used DNA image cytometry after Feulgen staining, which has the advantage of selecting only those epithelial cells in the cervical lesions. Bibbo et $a l^{16}$ also applied this methodology and detected aneuploidy in $21(48.8 \%)$ of 43 low grade lesions, but they did not detect HPV in their series. In our investigation, $75.5 \%$ of low grade lesions containing HPV DNA were aneuploid.

In extensive studies on large populations using sensitive methods of detecting DNA, such as PCR, the presence of oncogenic HPV was demonstrated in $43-68.6 \%$ of low grade lesions. ${ }^{68}$ In our investigation aneuploidy was detected in $75.5 \%$ of $68.6 \%$-that is, $51 \%$ of HPV positive low grade lesions. Therefore, the presence of aneuploidy in low grade lesions is suggestive of the presence of oncogenic HPV. Nevertheless, some authors have described aneuploid lesions containing non-oncogenic HPV types 6 and 11, but the presence of an unidentified associated oncogenic HPV could not be excluded in these cases as they were analysed using ISH alone. ${ }^{17-19}$

The two methodologies used to detect HPV DNA in the present study have somewhat different sensitivities, ranging from 20 to 50 viral copies/cell for ISH to one copy $/ 10^{6}$ cells for PCR. The aneuploid profile was found mainly in lesions with high viral copy numbers using ISH $(85 \%$ of low and $75 \%$ of high grade lesions), but low viral copy numbers, detected by PCR, were also associated with aneuploidy.

The multiploid pattern is particularly interesting. Multiploidy may be associated with a greater proclivity for genetic instability, partly attributable to the integration of viral DNA into the host genome. Most high grade lesions, particularly those containing HPV type 16, probably contain a mixture of integrated and episomal viral forms. However, in our study, a significant correlation was found between the HPV integration pattern observed on ISH, according to the criteria of Cooper et al,,$^{27}$ and multiploidy ( $92.6 \%$ of cases) and not between HPV integration and aneuploidy.

The frequency of the multiploid profile as a function of the grade of the lesion increased significantly from $35.9 \%$ in low grade lesions to $90.3 \%$ in CIN III lesions. Six patients who were followed, but not treated, underwent two successive biopsies. We observed a progression 
in the DNA profile from diploid to a single aneuploid peak and then to a multiploid profile parallelling the evolution from low to high grade CIN. Moreover, in $10 \mathrm{CIN}$ III lesions multiploid profiles, condylomas and CIN I lesions in the same section exhibited the same DNA profile and contained the same HPV type. Therefore, the discovery of a low grade lesion with a multiploid DNA profile and harbouring an oncogenic HPV type suggests that this lesion may progress to cancer or, alternatively, highlights the presence of a high grade lesion elsewhere in the section.

HPV DNA can now be detected in cervical lesions routinely and easily. DNA image cytometry is also widely used to predict of tumour prognosis. ${ }^{33}$ In our opinion, combining HPV DNA detection by both ISH and PCR with image cytometry may provide the pathologist and the physician with important prognostic information about low grade lesions, especially when these lesions harbour oncogenic HPV and have a multiploid DNA profile.

The authors sincerely thank Professor Philippe Birembaut and Dr Bernadette Visseaux-Coletto for helpful discussion, and Isabelle Duval for technical assistance. This work was supported by the ARC (Association pour la Recherche sur le Cancer) and by the Lions Club of Soissons; Stéphane Rihet was funded by a grant from the Conseil Régional de Picardie, France.

1 Zur Hausen H. Human papillomaviruses in anogenital cancer as a model to understand the role of viruses in human cer as a model to understand the

2 Koutsky LA, Holmes KK, Critchlow CW, Stevens CE, Paavoonen J, Beckman AM, et al. A cohort study of the risk of cervical intraepithelial neoplasia grade 2 or 3 in relation to papillomavirus infection. $N$ Engl f Med 1992;327:1272-8.

3 Bosch FX, Manos MM, Munoz N, Sherman ME, Jansen AM, Peto J, et al. International biological study on cervical cancer. Prevalence of human papillomavirus in cervical cancer: a worldwide prospective. I Natl Cancer Inst 1995;87:796-802.

4 Syriänen $K$, Mäntyjarvi $R$, Väyrynan $M$, Syrjänen $S$, Parkinen S, Yliskoski M, et al. Assessing the biological potential of human papillomavirus infections in cervical potential of human papillomavirus infections in cervical carcinogenesis. In: Steinberg BM, Brandsma JL, Taichman Harbor: Cold Spring Harbor Laboratory Press, 1987: 281-9.

5 Lorincz AT, Reid R, Jenson AB, Greenberg MD, Lancaster W, Kurman RJ. Human papillomavirus infection of the cervix: relative risk associations of 15 common anogenital types. Obstet Gynecol 1992;79:328-37.

6 Van den Brule AJC, Walboomers JMM, Du Maine M, Kenemans P, Meijer CJLM. Difference in prevalence of human papillomavirus genotypes in cytomorphologically normal papillomavirus genotypes in cytomorphologically normal intraepithelial neoplasia. Int $\mathcal{F}$ Cancer 1991;48:404-8.

7 Cuzick J, Terry G, Ho L, Hollingsworth T, Anderson M. Human papillomavirus type 16 DNA in cervical smears as a predictor of high-grade cervical intraepithelial neoplasia. Lancet 1992;339:959-60.

8 Cox JT, Lorincz AT, Schiffman MH, Sherman MH, Cullen A, Kurman RJ. Human papillomavirus testing by hybrid capture appears to be useful in triaging women with a cytocapture appears to be useful in triaging women with a cytosignificance. Am $\mathcal{F}$ Obstet Gynecol 1995;172:946-54.

9 Downey GP, Bavin PJ, Deery ARS, Crow J, Griffiths PD, Emery VC, et al. Relation between human papillomavirus type 16 and potential for progression of minor-grade cervical disease. Lancet 1994;344:432-5.

10 Syriänen KJ. Epidemiology of human papillomavirus (HPV) infections and their association with genital squamous cell cancer. APMIS 1989;97:957-70.

11 Monsonego J. Human papillomavirus (HPV), co-factors and carcinogenesis of the uterine cervix. In: Monsonego J, ed. Papillomaviruses in human pathology. Recent progress in epidermoid precancers. New York: Raven Press, 1990:31-48.

12 Remmink AJ, Walboomers JMM, Helmerhorst TJM Voorhorst FJ, Rozendal L, Risse EKJ, et al. The presence of persistent high-risk HPV genotypes in dysplastic cervical lesions is associated with progressive disease: natural history up to 36 months. Int $\mathcal{f}$ Cancer 1995;61:306-11.

13 De Vita R, Calugi A, Magi F, Mauro F, Montevecchi L, Vecchione A. Flow cytometry DNA analysis of the human cervix affected by human papillomavirus and/or intraepithelial neoplasia. Anal Quant Cytol Histol 1990;12:306-13.

14 Dudzinski MR, Haskill SJ, Fowler WC, Currie JL. DNA content of cervical neoplasia and its relationship to prognosis. Obstet Gynecol 1987;69:373-7.

15 Hedley DW, Friedlander MI, Taylor IW, Rugg CA, Musgrove EA. Method for analysis of cellular DNA content of paraffin-embedded pathological material using flow cytometry. 7 Histochem Cytochem 1983;31:1333-5.

16 Bibbo M, Dytch HE, Alenghat E, Bartels PH, Wied GL. DNA ploidy profiles as prognostic indicators in CIN lesions. Am $\mathcal{f}$ Clin Pathol 1989;92:261-5.

17 Chacho MS, Eppich E, Wersto R, Koss JG. Influence of human papillomavirus on DNA ploidy determination in genital condylomas. Cancer 1990;65:2291-4.

18 Clavel C, Zerat L, Binninger I, Boutterin M C, Polette M, Monsonego J, et al. DNA content measurement and in situ hybridization in condylomatous cervical lesions. Diagn Mo Pathol 1992;1:180-4.

19 Del Mistro A, Koss LG, Braunstein J, Bennett B, Saccomano G, Simmons KM. Condylomata acuminata of the urinary bladder. Am $\mathcal{F}$ Surg Pathol 1988,12:205-15. 20 Evans AS, Monaghan JM. Nuclear DNA content of normal,
neoplastic and "wart affected" cervical biopsies. Anal Quant Cytol Histol 1983;5:112-16.

21 Fu YS, Braun L, Shah KV, Lawrence WD, Robboy SJ. Histologic, nuclear DNA and human papillomavirus studies of cervical condylomas. Cancer 1983;52:1705-11.

$22 \mathrm{Fu}$ YS, Reagan JW, Richart RM. Definition of precursors. Gynecol Oncol 1981;12:S220-31.

23 Fujii T, Crum CP, Winkler B, Fu YS, Richart RM. Human papillomavirus infection and cervical intraepithelia neoplasia: histopathology and DNA content. Obstet Gynecol 1984;63:99-104.

24 Reid R, Crum CP, Herschmann BR, Fu YS, Braun L, Shah $\mathrm{KV}$, et al. Genital warts and cervical cancer III: subclinical and papillomaviral infection and cervical neoplasia are linked by a spectrum of continuous morphologic and biologic change. Cancer 1984;53:49-53.

25 Schevchuk MM, Richart RM. DNA content of condylom acuminatum. Cancer 1982;49:489-92.

26 Clavel C, Binninger I, Boutterin MC, Polette M, Birembaut P. Comparison of four non-radioactive and ${ }^{35} \mathrm{~S}$ based methodologies for the detection of human papillomavirus DNA by in situ hybridization. 7 Virol Methods 1991;33: 253-66.

27 Cooper K, Herrington CS, Stickland JE, Evans MF, O'D McGee J. Episomal and integrated human papillomavirus in cervical neoplasia shown by non-isotopic in situ hybridiin cervical neoplasia shown by non-isot

28 Binninger I, Clavel C, Polette M, Boutterin MC, Chypre C, Alpha $B$, et al. A new non isotopic detection of human papillomavirus DNA using polymerase chain reaction. Diagn Mol Pathol 1992;1:239-45.

29 Lorenzato M, Lallemand A, Visseaux-Coletto B, Gaillard D. Quantification de l'ADN par analyse d'image sur coupes en paraffine. Ann Pathol 1994;14:257-60.

30 Pei XF, Gorman PA, Watt FM. Two strains of human keratinocytes transfected with HPV 16 DNA: comparison with the normal parental cells. Carcinogenesis 1991;12:277-84.

31 Hurlin PJ, Kaur P, Smith PP, Perez-Reyes N, Blanton RA McDougall JK. Progression of human papillomavirus typ 18-immortalized human keratinocytes to a malignant phenotype. Proc Natl Acad Sci USA 1991;88:570-4.

32 Gilles C, Piette J, Rombouts S, Laurent C, Foidart JM. Immortalization of human cervical keratinocytes by human papillomavirus type 33. Int 7 Cancer 1993;53:872-9.

33 Herman CJ. Cytometric DNA analysis in the management of cancer. Cancer 1992;69:1553-6. 